\title{
Comparative study on levonorgestrel intrauterine system and oral progestogen in women with heavy menstrual bleeding in terms of efficacy, user satisfaction and quality of life using MMAS score
}

\author{
Krishna Dahiya $^{1}$, Supriya Mahipal ${ }^{1 *}$, Archit Dahiya ${ }^{2}$, Isha Nandal ${ }^{3}$, Priyanka Narang ${ }^{1}$
}

\author{
${ }^{1}$ Department of Obstetrics and Gynecology, Pt. B.D. Sharma PGIMS, Rohtak, Haryana, India \\ ${ }^{2}$ Department of Medicine, Pt. B.D. Sharma PGIMS, Rohtak, Haryana, India \\ ${ }^{3}$ Department of Obstetrics and Gynaecology, SGT Medical College, Gurgaon, Haryana, India
}

Received: 13 May 2019

Accepted: 01 July 2019

\section{*Correspondence:}

Dr. Supriya Mahipal,

E-mail: supriyam659@gmail.com

Copyright: () the author(s), publisher and licensee Medip Academy. This is an open-access article distributed under the terms of the Creative Commons Attribution Non-Commercial License, which permits unrestricted non-commercial use, distribution, and reproduction in any medium, provided the original work is properly cited.

\begin{abstract}
Background: To compare the efficacy, safety and user satisfaction of levonorgestrel intrauterine system (LNG-IUS) with oral progestogen in medical management of heavy menstrual bleeding (HMB).

Methods: This prospective study was conducted on 80 women with HMB in age group of 35-55 years. Patients were divided into two groups of 40 each and followed for six months. In Group I, LNG-IUS was inserted in post menstrual period and in Group II, patients received oral norethisterone $5 \mathrm{mg}$ twice a day during 5th-25th day of cycle for 6 months. Patients were evaluated about amount and duration of blood loss by pictorial blood assessment chart (PBAC) along with haemoglobin estimation on each follow up visit. MMAS (Menorrhagia Multi-Attribute Scale) score comparison between two groups was done to measure the improvement in quality of life. The results were analysed by using Chi-square test and Student t-test.

Results: Percentage reduction in PBAC score after six cycles of treatment was $89.3 \%$ in LNG IUS group as compared to $68 \%$ in norethisterone group. LNG-IUS was found to be more efficient in correcting anemia, lowering duration of bleeding and improving MMAS score as compared to norethisterone.

Conclusions: Present study showed that LNG IUS was superior to oral progestogen in decreasing quantity and duration of bleeding and improving overall quality of life over time.
\end{abstract}

Keywords: HMB, LNG-IUS, MMAS, PBAC, Satisfaction

\section{INTRODUCTION}

HMB is defined as a total blood loss of more than $80 \mathrm{ml}$ per cycle or a period of menstruation lasting more than 7 days. ${ }^{1}$ According to NICE 2007 guidelines heavy menstrual bleeding is defined as "excessive menstrual blood loss which interferes with a women's physical, emotional, social and material quality of life, and which can occur alone or in combination with other symptoms". ${ }^{2}$ The condition is often treated with oral medications (usually oral combined contraceptives, progesterone only pills taken for few months, tranexamic acid and NSAIDS) or conservative surgical management such as laser or hysteroscopic endometrial ablation or hysterectomy which is considered the definitive treatment for HMB. LNG-IUS containing 52mg levonorgestrel and releasing a therapeutic daily dose of levonorgestrel (20micrograms/day) for 5 years, is a potent progestin of 19-nortestosterone. It targets the endometrium directly by high local LNG concentrations that causes uniform 
suppression of endometrial proliferation and decidualisation of stroma. Therefore the present study has been done to evaluate the role of LNG-IUS in medical management of HMB in terms of efficacy and user satisfaction.

\section{METHODS}

This prospective study was conducted on 80 women having $\mathrm{HMB}$ in age group from 35 to 55 years attending OPD of Obstetrics and Gynaecology, Pt. B.D. Sharma Postgraduate Institute of Medical Sciences, Rohtak from September 2016-September 2017.

Women with pelvic inflammatory disease, myomas $>4$ cms, malignancy of genital tract, adnexal pathology, congenital uterine abnormality, post menopausal bleeding, medical illness like liver or heart disease, thromboembolism, hypertension, family history of breast cancer, allergy to progestins, concomitant use of enzyme inducing drugs like rifampicin, spironolactone, valproate were excluded from the study.

A written informed consent was taken from all patients included in study. A detailed menstrual history including duration of bleeding, cycle length, passage of clots, no. of pads used was taken from all patients. Blood loss assessed by pictorial blood assessment chart (PBAC) developed by Hingham et al with cut off value of $100 .{ }^{3} \mathrm{~A}$ general physical and systemic examination was conducted in all patients. Per speculum and bimanual vaginal examination was done to rule out any pelvic pathology. Transvaginal ultrasonography was done post menstrually to measure the thickness of endometrium and to exclude submucosal myomas, endometrial polyps and adnexal pathology. Pap smear and endometrial sampling was performed in all women included in study. Laboratory tests including haemoglobin levels, coagulation and thyroid profile was done.

Patients were divided into two groups with 40 patients in each group by using random allocation table. In study group LNG-IUS was inserted in the post menstrual period and in control group norethisterone $5 \mathrm{mg}$ twice a day was given orally on 5 th-25th day for 6 cycles.

Patients were assessed by PBAC scoring in first, third and sixth months of the treatment. A transvaginal ultrasonography was done after 6 months to assess reduction in endometrial thickness and size of myomas, if any. Hemoglobin levels were evaluated at 3rd and 6th month of the study and was compared with initial baseline levels. Side effects of medications were recorded. Patients were asked to respond 'yes' or 'no' if they were satisfied or not satisfied with the treatment. Quality of life evaluation was done using MMAS (Menorrhagia Multi-Attribute Scale) which has been designed to measure the effect of HMB on six domains of daily life i.e. family life and relationships; physical health; work and daily routine; practical difficulties; psychological health and social life; with possible responses of not affected/slightly affected/moderately affected/severely affected for each domain. ${ }^{4}$

\section{Outcome}

The primary outcome was determined by reduction in amount and duration of menstrual bleeding and improvement in haemoglobin levels.

Secondary outcome was evaluated by adverse effects, acceptability, user satisfaction and continuation of treatment.

\section{Statistical analysis}

At the end of study the data was statistically analysed by using SSPS version 17. The results were analysed by using Chi-square test and Student t-test. A p-value less than 0.05 were considered as statistically significant.

\section{RESULTS}

Eighty five women with eligible criteria were recruited in the study and were randomized into 2 treatment groups. Two patients in group I reported expulsion of device and one patient got it removed due to uncontrolled bleeding. One patient in group II was lost to follow-up and one patient used the medication inappropriately. Results of forty patients in each group who were completing the study were finally analysed.

Table 1: Baseline characteristics of patients in two groups.

\begin{tabular}{|c|c|c|}
\hline Parameters & $\begin{array}{l}\text { Group I }(\mathrm{n}=40) \\
\text { LNG- IUS }\end{array}$ & $\begin{array}{l}\text { Group II ( } \mathrm{n}=40) \\
\text { Norethisterone }\end{array}$ \\
\hline \multicolumn{3}{|c|}{ Age range (years) } \\
\hline Mean \pm SD & $43.67 \pm 4.55$ & $43.7 \pm 4.81$ \\
\hline Range & $35-52$ & $36-52$ \\
\hline \multirow[b]{2}{*}{ SE status } & LM- 21(52.5\%) & LM-25 (62.5\%) \\
\hline & $\begin{array}{l}\text { UM- } 19 \\
(47.5 \%)\end{array}$ & UM-15 (37.5\%) \\
\hline \multicolumn{3}{|l|}{ Parity } \\
\hline $\mathrm{P} 1$ & $5(12.5 \%)$ & $4(10 \%)$ \\
\hline $\mathrm{P} 2$ & $16(40 \%)$ & $12(30 \%)$ \\
\hline$>\mathrm{P} 3$ & $19(47.5 \%)$ & $24(60 \%)$ \\
\hline \multirow{2}{*}{ Literacy } & $\begin{array}{l}\text { Illiterate }-12 \\
(30 \%)\end{array}$ & $\begin{array}{l}\text { Illiterate-15 } \\
(37.5 \%)\end{array}$ \\
\hline & $\begin{array}{l}\text { Literate-28 } \\
(70 \%)\end{array}$ & $\begin{array}{l}\text { Literate-25 } \\
(62.5 \%)\end{array}$ \\
\hline $\begin{array}{l}\text { PBAC score } \\
(\text { mean } \pm S D)\end{array}$ & $276.25 \pm 39.24$ & $274.72 \pm 39.51$ \\
\hline $\begin{array}{l}\text { Duration of } \\
\text { bleeding (days) } \\
(\text { mean } \pm \text { SD) }\end{array}$ & $13.9 \pm 2.35$ & $13.22 \pm 3.30$ \\
\hline Mean $\mathrm{Hb}(\mathrm{g} / \mathrm{dl})$ & $8.70 \pm 1.16$ & $9.09 \pm 1.09$ \\
\hline $\begin{array}{l}\text { MMAS score } \\
(\text { mean } \pm S D)\end{array}$ & $36.97 \pm 4.34$ & $36.17 \pm 4.55$ \\
\hline
\end{tabular}


Demographic data and basal values of $\mathrm{Hb}$, PBAC score, duration of bleeding and MMAS score were comparable in two groups (Table 1).

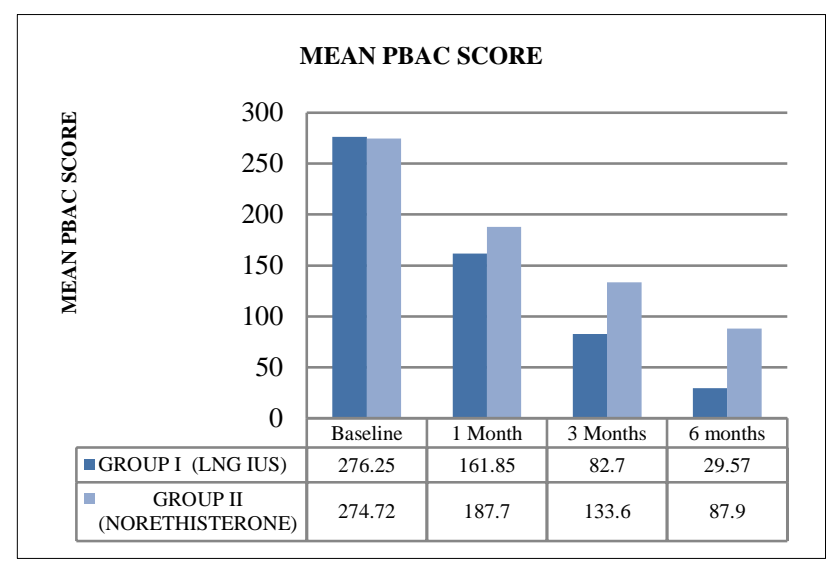

Figure 1: Comparison of PBAC score in two groups.
It was observed in our study that mean PBAC score at the time of enrollment was $276.25 \pm 39.24$ in group I and $274.72 \pm 39.51$ in group II. Highly significant reduction in PBAC score was witnessed in both groups at 3rd and 6th month of follow up but group I exhibited more reduction in PBAC score on both occasions $(\mathrm{p}=0.000)$ as shown in Figure 1.

Changes in PBAC score differed between the two groups in statistically significant manner in each follow up visit. In the present study, PBAC score reduced by $89.3 \%$ in LNG-IUS group as compared to $68 \%$ in NETA group in 6 months which is highly significant reduction $(\mathrm{p}=0.000$; Table 2).

Both treatment modalities reduced the duration of bleeding with each cycle, but there was significantly more reduction in LNG-IUS group as compared to oral progestogen (Table 3 ).

Table 2: Difference of mean PBAC scores (baseline versus 6 months).

\begin{tabular}{|llll|}
\hline Mean score & Group I $(\mathbf{n}=40)$ LNG IUS & Group II $(\mathbf{n}=40)$ Norethisterone & $\begin{array}{l}\text { Statistical significance } \\
\text { Baseline }\end{array}$ \\
\hline $276.25 \pm 39.24$ & $274.72 \pm 39.51$ & $\begin{array}{l}\mathrm{p}=0.862 \text { (NS) } \\
95 \% \text { CI }-19.06 \text { to } 16.0\end{array}$ \\
\hline 6 months & $29.57 \pm 27.21$ & $87.9 \pm 53.67$ & $\begin{array}{l}\mathrm{p}=0.000 \text { (Sig.) } \\
95 \% \text { CI } 39.39 \text { to } 77.27\end{array}$ \\
\hline Mean difference & $246.77 \pm 33.49$ & $186.82 \pm 36.10$ & $\begin{array}{l}\mathrm{p}=0.000 \text { (Sig.) } \\
95 \% \text { CI }-75.45 \text { to }-44.45\end{array}$ \\
\hline \% reduction & $89.3 \%$ & $68 \%$ & \\
\hline
\end{tabular}

Table 3: Reduction in duration of bleeding (days).

\begin{tabular}{|llll|}
\hline Duration & $\begin{array}{l}\text { Group I }(\mathrm{n}=40) \\
\text { LNG IUS }\end{array}$ & $\begin{array}{l}\text { Group II (n=40) } \\
\text { Norethisterone }\end{array}$ & Statistical significance (Gr. I vs. II) \\
\hline Baseline & $13.9 \pm 2.35$ & $13.22 \pm 3.30$ & $\mathrm{p}>0.05$ (NS) $95 \%$ CI 1.85 to 4.41 \\
\hline 1 Month & $8.7 \pm 2.65$ & $10.5 \pm 3.70$ & $\mathrm{p}<0.01$ (Sig.) $95 \%$ CI 0.37 to 3.23 \\
\hline 3 Months & $5.9 \pm 3.12$ & $7.7 \pm 3.90$ & $\mathrm{p}<0.05$ (Sig.) $95 \%$ CI 0.23 to 3.37 \\
\hline 6 months & $2.77 \pm 2.13$ & $5.15 \pm 3.77$ & $\mathrm{p}<0.05$ (Sig.) $95 \%$ CI -0.12 to 2.88 \\
\hline $\begin{array}{l}\text { Statistical significance } \\
\text { (Baseline vs. } 6 \text { months) }\end{array}$ & $\begin{array}{l}\mathrm{p}=0.000 \\
\text { (Sig.) }\end{array}$ & $\begin{array}{l}\mathrm{p}=0.000 \\
\text { (Sig.) }\end{array}$ & \\
\hline
\end{tabular}

Table 4: MMAS (Menorrhagia Multi-Attribute Scale) score.

\begin{tabular}{|llll|}
\hline MMAS & $\begin{array}{l}\text { Group I }(\mathrm{n}=40) \\
\text { LNG IUS }\end{array}$ & $\begin{array}{l}\text { Group II }(\mathrm{n}=40) \\
\text { Norethisterone }\end{array}$ & Statistical signifficance \\
\hline Baseline & $36.97 \pm 4.34$ & $36.17 \pm 4.55$ & $\mathrm{p}=0.423$ (NS) $95 \%$ CI -2.78 to 1.18 \\
\hline Follow-up & $82.4 \pm 4.85$ & $71.10 \pm 8.03$ & $\mathrm{p}=0.000$ (Sig.) $95 \%$ CI -14.25 to -8.35 \\
\hline $\begin{array}{l}\text { Statistical significance } \\
\text { (Baseline vs. Follow-up) }\end{array}$ & $\begin{array}{l}\mathrm{p}=0.000 \\
\text { (Sig.) }\end{array}$ & $\begin{array}{l}\mathrm{p}=0.000 \\
\text { (Sig.) }\end{array}$ & \\
\hline
\end{tabular}

The incidence of spotting was comparable in both groups in each cycle. Eight patients in group I and five in group II had spotting at the end of six months. Twelve patients $(30 \%)$ in LNG IUS group had amenorrohea as compared to five patients $(12.5 \%)$ in NETA group at 6th month follow up which was statistically significant $(\mathrm{p}=0.050)$. It was found that $30(75 \%)$ patients in group I and 27 $(67.5 \%)$ patients in group II had either scanty or no 
bleeding. There was significant increase in mean haemoglobin levels in both treatment groups from baseline to six months $(\mathrm{p}=0.000)$. However LNG IUS was more successful in treating anemia when compared to norethisterone $(\mathrm{p}=0.000)$.

We found that significantly more number of patients complained of lower abdominal pain in group I $(p=0.023)$, which was well tolerated except one patient who requested for removal of IUS due to excessive pelvic pain despite of good control in bleeding. One patient $(2.5 \%)$ reported severe acne in group I and discontinued treatment after 6 months. Eight patients (20\%) with LNG IUS had incidental finding of ovarian cyst on USG which were $<5 \mathrm{~cm}$ in size with no symptoms and resolved spontaneously. Nine patients $(22.5 \%)$ in group II complained of bloating and breast tenderness and eight patients $(20 \%)$ had weight gain. Two patients $(5 \%)$ had both headache and lower abdominal pain.

A total of $36(90 \%)$ women in group I and $29(72.5 \%)$ women in group II were found to be satisfied in our study $(p=0.000)$ at the end of 6 months.

MMAS score (designed to measure the effect of heavy menstrual bleeding on quality of life) comparison between two groups was done which showed significant improvement in both groups $(\mathrm{p}=0.000)$ but this improvement was higher among patients assigned to LNG IUS as compared to norethisterone group ( $\mathrm{p}=0.000$; Table 4).

\section{DISCUSSION}

The primary objective of treating HMB is to reduce the amount of menstrual loss and to improve quality of life. The first choice of treatment in idiopathic HMB should be the least invasive and the least expensive medical therapy available among the wide variety of medications in use, including hormonal and non-hormonal agents. ${ }^{5}$ The condition is often treated with hormones, usually oral combined contraceptives or progesterone only pills taken for few months. Hysterectomy is considered the definitive treatment for heavy menstrual bleeding with high success rates but it is a major surgery with relatively high incidence of short term complications such as bleeding, infection and wound healing problems along with lengthy post operative recovery period. Various studies have established the superiority of LNG IUS over other treatments in reducing blood loss in women with HMB. Eighty percent of women with HMB had no structural abnormalities in uterus which makes use of LNG-IUS a better alternative to other treatment modalities; which is in line with our study where twenty percent of women had anatomical pathology.

Highly significant reduction in PBAC score was witnessed in both groups at 3rd and 6th month of follow up but group I exhibited more reduction in PBAC score on both occasions $(\mathrm{p}=0.000)$.
Percentage reduction in PBAC score after six cycles of treatment was $89.3 \%$ in LNG IUS group as compared to $68 \%$ in norethisterone group which clearly demonstrates that LNG IUS is very effective in reducing menstrual blood loss in patients with heavy menstrual bleeding. This result is in concordance with Kiseli et al study, where percentage decrease in PBAC score was reported to be $85.8 \%$ in LNG IUS group and $53.1 \%$ in norethisterone group. ${ }^{6}$ In a study done by Ashraf et al, $94.73 \%$ reduction in LNG IUS group was noted as compared to $73 \%$ in norethisterone treated group at 6 months. ${ }^{7}$ It was observed that both the treatment modalities significantly decreased bleeding duration at completion of study $(\mathrm{p}=0.000)$; LNG IUS was more successful than norethisterone in lowering duration of bleeding which was also witnessed in the study done by Lee et al, who compared LNG IUS with conventional medical therapy. ${ }^{8}$ Kriplani et al reported a significant decrease in mean days of bleeding at one month with LNG IUS and the decrease continued with treatment duration. ${ }^{9}$ It was seen in our study that 38 (95\%) women reported alteration in menstrual pattern, out of which 18 $(45 \%)$ reported decrease in amount of bleeding, $8(20 \%)$ had spotting and $12(30 \%)$ had amenorrhea after 6 month follow up in LNG IUS group. Kriplani et al, also observed amenorrhea rate of $28.57 \%$ in LNG IUS users after 6 months. ${ }^{9}$

In our study, LNG IUS as well as norethisterone were found to be effective in restoring haemoglobin levels at both 3rd and 6th months of study. It was observed that LNG IUS was more superior in correcting anemia as compared to norethisterone. Kiseli et al, studied 40 women with heavy menstrual bleeding and observed that LNG IUS had more haemoglobin, serum iron and ferritin levels as compared to norethisterone at 6th treatment cycle. ${ }^{5}$ Similar results were observed by Mewat et al and Kaunitz et al in their trials. ${ }^{10,11}$ A total of $36(90 \%)$ women in group I and $29(72.5 \%)$ women in group II were found to be satisfied in our study $(\mathrm{p}=0.000)$. Romer et al reported the satisfaction level of $95 \%$ among patients using LNG IUS. ${ }^{12}$ Backman et al also observed that most of the LNG IUS users were very or fairly satisfied with its use. ${ }^{13}$ In contrast to our study, Kiseli et al reported comparable satisfaction level between both groups i.e. $70 \%$ in norethisterone group and $77 \%$ in LNG IUS users. ${ }^{5}$ In a study by Naqaish et al who compared LNG IUS with norethisterone in 92 patients with DUB, it was observed that $90 \%$ patients in group I were highly satisfied as compared to only $20 \%$ patients in group II. ${ }^{14}$ MMAS score was significantly improved in both treatment groups but improvement was statistically higher with LNG IUS users as compared to norethisterone group $(\mathrm{p}<0.001)$.

Eralil et al, demonstrated that all six domains of MMAS favoured the LNG IUS at completion of study. ${ }^{15}$ In a pragmatic, multicenter trial ECLIPSE, patient reported score on menorrhagia multi attribute scale (MMAS) was assessed over two year period and it was reported that 
MMAS scores were improved from baseline to 6 months in both groups but improvement was significantly greater in LNG IUS group which is in concordance with our study. ${ }^{4}$

\section{CONCLUSION}

Present study showed that both LNG IUS and norethisterone were effective in reducing $\mathrm{HMB}$ but patient's satisfaction rates were higher in LNG IUS users which was found to be superior to oral progestogen in improving quality of life parameters in affected women and more patients continued to use it beyond six months as most of their problems were better resolved with it. Higher rate of systemic side effects with norethisterone and decrease compliance for taking pills on daily basis has made it a less favourable option for long term use as compared to LNG IUS which has an advantage of fit and forget method rather than relying on patient's compliance. So in conclusion, LNG IUS is an excellent treatment option in medical management of HMB which is a better alternative to other medical methods. However larger study with long term follow-up is required to reach better conclusion.

Funding: No funding sources

Conflict of interest: None declared

Ethical approval: The study was approved by the Institutional Ethics Committee

\section{REFERENCES}

1. Hallberg L, Nilsson L. Determination of menstrual blood loss. Scand J Clin Lab Invest. 1964;16:244-8.

2. Liu Z, Doan QV, Blumenthal P, Dubios RW. A Systematic review evaluating health related quality of life, work impairment and health care costs and utilization in abnormal uterine bleeding. Value Hlth. 2007;10:183-94.

3. Higham JM, Shaw RW. Clinical associations with objective menstrual blood volume. Eur J Obstet Gynaecol Reprod Biol. 1999;82:73-6.

4. Gupta J, Kai J, Middleton L, Pattison H, Gray R, Daniels J, et al. Levonorgestrel intrauterine system versus medical therapy for menorrhagia. N Engl J Med. 2013;368:128-37.

5. Pinkerton IV. Pharmacological therapy for abnormal uterine bleeding. Menopause. 2011;18:459-61.

6. Kiseli M, Kayikcioglu F, Evliyaoglu O, Haberal A. Comparison of therapeutic efficacies of norethisterone, tranexamic acid and levonorgestrel- releasing intrauterine system for the treatment of heavy menstrual bleeding: a randomised controlled study. Gynecol Obstet Invest. 2016;81:447-53.

7. Ashraf MN, Agha Habib-ur-Rehman, Shehzad Z, Alsharari SD, Murtaza G. Clinical efficacy of levonorgestrel and norethisterone for the treatment of chronic abnormal uterine bleeding. J Pak Med Assoc. 2017;67:1331-8.

8. Lee BS, Xing X, Asif S. Levonorgestrel releasing intrauterine system versus conventional medical therapy for heavy menstrual bleeding in the Asia Pacific region. Int J Gynaecol Obstet. 2013;121:2430.

9. Kriplani A, Singh BM, Lal S, Agarwal N. Efficacy, acceptability and side effects of the levonorgestrel intrauterine system for menorrhagia. Int J Gynaecol Obstet. 2007;97:190-4.

10. Kaunitz AM, Inki P. The levonorgestrel-releasing intrauterine system in heavy menstrual bleeding: A benefit-risk review. Drugs. 2012;72:193-215.

11. Mawet M, Nollevaux F, Nizet D, Wijzen F, Gordenne V, Tasev N. Impact of a new levonorgestrel intrauterine system, Levosert $\AA$, on heavy menstrual bleeding: results of a one-year randomised controlled trial. Eur J Contracep Reprod Hlth Care. 2014;19:169-79.

12. Romer $\mathrm{T}$, Linsberger. User satisfaction with a levonorgestrel releasing intrauterinesystem (LNGIUS). Data from an international survey. Eur $\mathbf{J}$ Contracept Reprod Hlth Care. 2009;14:391-8.

13. Backman T. Benefit-risk assessment of the levonorgestrel intrauterine system in contraception. Drug Saf. 2004;27:1185-204.

14. Naqaish T, Rizvi F, Khan A, Afzal M. Patient satisfaction for levonorgestrel intrauterine system and norethisterone for treatment of dysfunctional uterine bleeding. J Ayub Med Coll Abbottabad. 2012;24:23-6.

15. Eralil GJ. Levonorgestrel releasing intrauterine system in the treatment of heavy menstrual bleeding. J Obstet Gynecol India. 2016;66:505-12.

Cite this article as: Dahiya K, Mahipal S, Dahiya A, Nandal I, Narang P. Comparative study on levonorgestrel intrauterine system and oral progestogen in women with heavy menstrual bleeding in terms of efficacy, user satisfaction and quality of life using MMAS score. Int J Reprod Contracept Obstet Gynecol 2019;8:3073-7. 